authors have contributed. Inevitably the chapters represent individual views and the reader must integrate for himself, in order to arrive at a collective appraisal.

Volume 2 contains a chapter on the theory of antenna arrays by R. S. Elliott, which will be mentioned again later; the remaining 330 pages are devoted to the elements of the array and problems of mutual coupling. These three chapters are the work of A. A. Oliner and R. G. Malech, the first of which contains a comprehensive review of the properties of elements such as slots, horns, dipoles and spiral antennas, with a description of their individual mode of operation and the influence of mutual coupling. The theory is particularly clear, and in this respect Oliner is able to draw on many years of experience in solving problems in this field. His co-author brings considerable practical experience to bear, and many illustrations and results, as elsewhere in the volumes, come from industrial and government reports. This is possibly one of the most important features of the entire work, for the prime motivation for research and development on antenna scanning has been, and still is, military radar. The treatment of mutual coupling is divided between two chapters; one on infinite arrays, the other on finite arrays, the approach being to consider the infinite array and then account for edge effects eaused by the finiteness of the array. The discussion of the theory is presented in considerable detail and in a manner particularly valuable to research workers seeking a fundamental understanding of the subject. From a practical standpoint, the final chapter will be of special value and included are recently suggested techniques for compensating mutual coupling on scan. Those considered include exterior modifications to the array and feed compensation. The first chapter on array theory, which in some ways is more relevant to Volume 3 , gives a comprehensive account of linear arrays and pattern synthesis; planar arrays and volume arrays are briefly mentioned. Final consideration is given to the recent development of nonuniformly spaced arrays.

In Volume 3 the implementation of scanning is treated. In the first chapter W. H. Kummer considers the way in which a microwave array antenna can be fed, and techniques for providing phase-scan are described. These include electromechanical and electronic methods. Most of the latter section is given over to ferrite and diode phase-shifters, which is appropriate, but, as is inevitable, the reader will be conscious of the fact that no material more recent than 1964 is included. The second chapter, on frequency scanning, is by N. A. Begovitch of Hughes, a company which has pioneered many developments in the field. The theoretical treatment is thorough and the problem of short pulses is usefully discussed. The most recent reference given is dated 1963 and most are earlier than 1962. This is perhaps only unfortunate in that independent British work is not documented and the dearth of other than United States references in certain chapters is a point for the reader to bear in mind. J. L. Butler provides a chapter on digital, matrix and intermediate frequency scanning. The author is well known for his own contribution to this field and the chapter includes an account of the so-called Butler matrix. There are copious references which, in places, the uninformed reader will have to consult. R. W. Bickmore introduces the concept of an antenna system possessing one or more time dependent parameters. The theory of the timedomain principle is developed and concepts such as modulation "tagged" multiple beams and synthetic aperture are explained. Practical examples are discussed and a Hughes system is explained in some detail. The concluding chapter by D. L. Margerum is concerned with self-phased or adaptive arrays in which each element is phased, based on the information obtained from signals received. A critical appraisal of the self-phased array is given and theory and applications are described. The retrodirective array is discussed with particular reference to that pro- posed by Van Atta, and problems associated with selfphased radar arrays are considered.

The volumes will be welcomed by those engaged in research and development on radar inertialess scanning systems. Others engaged in antenna studies will find them valuable works of reference. Certain chapters can be recommended to postgraduate students following courses in antenna theory and practice. In conclusion, it seems probable that, in time, the volumes will become as familiar to radar antenna engineers as Silver's M.I.T. 12.

P. J. B. Clarricoats

\section{USES FOR POWDER}

\section{Modern Developments in Powder Metallurgy}

Edited by Henry H. Hausner. (Proceedings of the 1965 International Powder Metallurgy Conference.) Vol. 1: Fundamentals and Methods. Pp. xiv +398. Vol. 2: Applications. Pp. xii +350 . Vol. 3: Development and Future Prospects. Pp. xii +275 . (New York: Plenum Press, 1966.) $\$ 80$ the set.

Any book with the title of the type Recent Advances in ... brings to mind the picture of an editor with a series of contributions from well-known authorities that have to be made into a coherent whole. There are added problems in books of this kind, in that the contributor often does not produce quite what the editor would wish, and also that, being specialists, the authors tend to bias their writing to their own particular activity, with the result that a series of articles is produced, rather than a book with a unified theme or treatment running through it.

These observations are true of Modern Developments in Powder Metallurgy. In the three volumes there are some sixty-two papers which cover practically every aspect of the subject, from the production of powder to a consideration of future developments, and in these papers reference is made to the majority of metals and methods in present day use. The tone of the papers is not uniform, as some may be stated to be phenomenological, others technological, while some have a strong mathematical bias.

Volume 1 is entitled Fundamentals and Methods and is broadly sub-divided into sections dealing with the production of powders, powder testing, consolidation and sintering. The title of Volume 2, Applications, is somewhat misleading, for it implies that consideration should be given to the use of products made by powder metallurgy, whereas most of the papers are concerned with what might be termed "the metallurgy of powder metallurgy". There are papers on, for example, the activated sintering of iron powder, the mechanisms of plastic deformation of SAP type alloys and a most interesting comparison between the properties of nickel-base creepresisting alloy made by powder metallurgy, with a similar alloy made by conventional methods. It is probably in the final volume that most reference to applications is found, when the contributions refer to nuclear applications and the use of some specialized products of powder metallurgy, in addition to thoughts on the present position and future trends of the industry.

The overall title of these volumes is accurate, and they will be valuable to those who possess a background knowledge in the subject. In spite of the fact that, in a number of cases, the photomicrographs have suffered in reproduction, that the legends on a number of the figures are hard to read and that some expressions used are unusual, the objective stated by the editor in the introduction to Volume 1, that "the most important role of the content of the volume is to stimulate new ideas for further development in powder metallurgy", does apply to all three volumes, and they will be of great value to all who are interested in powder metallurgy.

\section{B. L. Danieli}

